\title{
White certificates and white certificate trading schemes as greenhouse gas mitigation policy options for South Africa
}

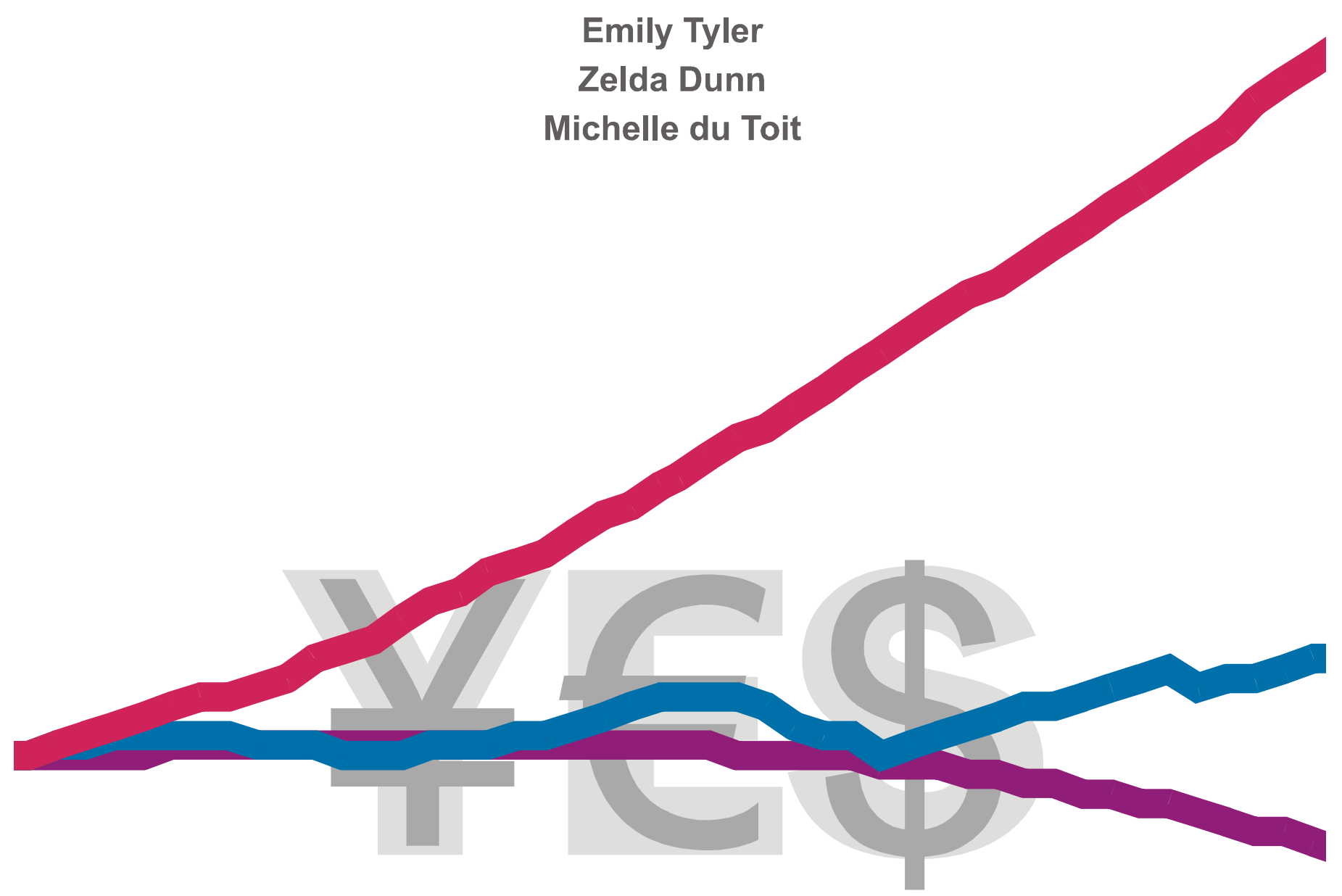

Energy Research Centre

E. UNIVERSITY OF CAPE TOWN 


\title{
White certificates and white certificate trading schemes as greenhouse gas mitigation policy options for South Africa
}

\author{
EMILY TYLER \\ ZELDA DUNN \\ MICHELLE DU TOIT
}

\section{G: ENESIS \\ 중 EPRU \\ Environmental Policy Research Unit}




\section{Acknowledgements}

These reports are the result of collaboration between the Energy Research Centre (ERC), Environmental Policy Research Unit (EPRU) and Genesis Analytics. ERC and EPRU are both research units at the University of Cape Town. The research by Genesis Analytics was commissioned by ERC, drawing on NRF funding which is gratefully acknowledged. The individual reports may also appear in other report series. 


\section{Contents}

$\begin{array}{ll}\text { 1. White certificate schemes } & 1\end{array}$

1.1 What is a white certificate (trading) scheme? 1

1.2 International examples of WCSs 1

1.3 White certificate scheme designs 2

1.3.1 Targets 3

1.3.2 Point of regulation or obligation 3

1.3.3 Eligible technologies 3

$\begin{array}{lll}\text { 1.3.4 Monitoring and verification } & 3\end{array}$

$\begin{array}{lll}1.3 .5 & \text { Trading } & 4\end{array}$

1.3.6 Banking 4

1.3.7 Additionality and baselines 4

1.4 Lessons from international experience 4

1.5 White certificate trading and interaction with greenhouse gas mitigation policy instruments 5

2. WCS as a greenhouse gas mitigation policy option for South Africa 6

2.1 Relevant characteristics of the South African energy sector 6

$\begin{array}{lll}2.2 & \text { Current energy sector policy context } & 7\end{array}$

2.3 WCS as a greenhouse gas mitigation instrument in South Africa 7

2.3.1 Comments based on the application of theory and international experience to the South African context 8

$\begin{array}{ll}\text { 2.3.2 Areas for further research } & 8\end{array}$

$\begin{array}{ll}\text { References and bibliography } & 10\end{array}$ 


\section{White certificate schemes}

\subsection{What is a white certificate (trading) scheme?}

A white certificate, which is also referred to as an Energy Saving Certificate (ESC), or an Energy Efficiency Credit (EEC), is an instrument awarded by an authorisation body to guarantee that a specific amount of energy savings has been achieved. Each certificate is a unique and traceable commodity carrying a property right over a certain amount of additional energy savings and certifying that the benefit of these savings has not been accounted for elsewhere (EuroWhiteCert Project, 2006).

The precise definition of a White Certificate Scheme (WCS) is not yet clear in either the literature or in practice. Some authors and practitioners distinguish a WCS on the basis of trading, whilst others don't make trading a pre-requisite. In most cases some form of flexibility in achieving targets is important, but this may not necessarily be through trading as such. For example, the World Energy Council increased its definition of White Certificates to include 'all' forms of Energy Efficiency Obligations that are in place even if they do not work in conjunction with tradable certificate'. The defining feature in their definition is that there should be an improvement in the efficiency with which end-use customers use energy from energy companies (Lees, 2007). The full range of schemes considered in the literature or implemented is considered in this paper, with a focus on those with a trading element.

Participants in WCSs are typically suppliers or distributors of electricity, gas and oil, and are required to perform energy efficiency measures that are consistent with a pre-defined percentage of their annual supply. If these energy producers and / or suppliers do not meet their mandated targets, they are required to pay a penalty. White certificates are awarded to the participant when an amount of energy is saved, the producer can then use the certificate for their own compliance purposes or can sell it to other parties in order to meet their compliance. Technology coverage by the white certificates varies from scheme to scheme (EuroWhiteCert Project, 2006).

Key players in WCSs as implemented or designed to date are the government bodies who set up the schemes and appoint bodies to control their operation, retail energy suppliers or distributors who are obligated to meet targets, and both energy service companies (ESCOs) that can create certificates from energy saving projects and housing corporations that can create certificates from building renovations (EuroWhiteCert Project, 2006).

WCSs which involve trading are baseline-and-credit type trading schemes (see the Emissions Trading paper in this series), with targets which are intensity based (per unit of energy consumed) as opposed to absolute levels of energy consumption. This characteristic is particularly important when considering WCSs as a greenhouse mitigation policy instrument (Capozza, 2006), as emissions reduction achieved under a WCS are necessarily relative rather than absolute.

From a greenhouse gas emissions reduction perspective, WCSs are an indirect policy instrument, as their primary objective is energy efficiency. However, to the extent that the energy saved is generated from fossil fuels, a significant volume of greenhouse gas emissions can be achieved.

\subsection{International examples of WCSs}

WCSs are not widely used internationally, and there are very few examples of those incorporating trading in its pure form. Hybrids abound, and energy efficiency targets are common. Emissions Trading Schemes (ETSs) where energy efficiency projects dominate can also be considered as a type of WCS. WCSs appear to be most prevalent in Europe, the US and Australia, with very little information on WCSs in developing countries (Lees, 2007). Many WCSs cover the residential sectors (Netherlands, UK), with examples of industry level WCSs less common. 
In Europe, several countries have implemented, or are considering implementing energy efficiency obligations (for example Belgium, Denmark, France, Ireland, Italy and the United Kingdom), some of which have scope for certificate trading. The obligated entities in these countries are energy suppliers or distributors ranging from only electricity to all energy including the end-use sectors to which these obligations apply. In most cases the targets are set by the government (Lees, 2007). These energy efficiency schemes have proved to be very flexible and have worked in both monopoly energy utilities and in liberalised energy markets (Lees, 2007). Trading within the scheme currently exists only in France, Italy and the UK. Compliance has been achieved in European schemes by almost all participants, without resorting to penalties.

Italy started a WCS in January 2005, including all energy end-use sectors, as well as intermediate users in the gas sector. Targets are set for distributors of electricity and gas. Targets can be met through either a reduction in electricity consumption, a reduction in natural gas consumption or a reduction in the consumption of fossil fuels, resulting in three types of white certificates that can be created by the scheme. Fifty percent of the target allocated needs to be achieved through either electricity or gas saving, the remaining amount may be achieved through the reduction in fossil fuels (Oikonomou, 2004; EuroWhiteCert Project, 2006). Design, implementation and compliance is carried out by the Authority for Electricity and Gas.

Although the UK has no white certificate as such, it has implemented two schemes dealing with energy efficiency in the household sector. The first was the Energy Efficient Commitment (EEC) scheme which ran from 2005 to 2008 . The aim of the scheme was to stimulate energy efficiency within the household sector in the UK, where over 50 percent of national energy savings are to be realised. The EEC did not provide tradable certificates as such but did allow trading of energy savings as well as trading of individual obligations which was facilitated through OFGEM (Oikonomou, 2004).

The EEC has been superceded by the Carbon Emissions Reduction Target (CERT) which runs from $2008-2011$ and aims to reduce 154 million tonnes of $\mathrm{CO}_{2}$ by 31 March 2011. CERT is a mandatory scheme and is supported by The Electricity and Gas Order of 2008. The overall target within CERT is apportioned by the UK energy regulator, the Office of Gas and Electricity Markets (OFGEM) to gas and electricity suppliers that have a minimum of 50000 customers. Each supplier's individual target is known as its carbon obligation. Suppliers meet their carbon obligations through various energy efficiency activities e.g. subsidising cavity wall insulation or delivering free compact fluorescent lamps (CFLs) to low-income households. Many of these activities are subcontracted out. Trading is allowed between obligated parties and there is intertemporal flexibility in that trades can take place over different obligation periods (Lees, 2007). OFGEM assesses activities to ensure energy savings and therefore carbon emission reductions are taking place. Under CERT a minimum of $40 \%$ of the overall target needs to be focussed at low-income households or the elderly (OFGEM, Carbon Emission Reduction Target). The UK government is investigating introducing white certificate trading after 2001 for non-obligated parties (Lees, 2007).

In the US, Connecticut, Pennsylvania, and Nevada have Energy Efficiency Portfolio Standards that require regulated utilities to meet a target of their project power needs through energy efficiency. Utilities must meet their obligations by either reducing their consumer's energy usage, or by purchasing white certificates.

A WCS can be understood to be in place in New South Wales in Australia, as a component of the Greenhouse Gas Abatement Scheme (GGAS). Certificates for use in the GGAS can be generated through energy efficiency projects, which are often undertaken by energy management firms. This outsourcing represents the ability of the energy savings to be undertaken by different entities to those which are regulated under the GGAS.

\subsection{White certificate scheme designs}

WCS vary considerably in their design and definition. Where trading is a component of a WCS, many of the design considerations for an emissions trading scheme or green certificate trading 
scheme will apply (see the papers on these topics as part of this series). Descriptions of the common design features of white certificate schemes follow below.

\subsubsection{Targets}

Targets can be mandatory or voluntary, and are expressed as a reduction in energy use from a specific baseline. Both the target setting and sectors involved are usually decided by the government as opposed to the energy regulator of the country. This is advantageous as energy efficiency obligations are part and parcel of the environmental concerns of a country and have implications on social aspects of the nation. These targets are often set according to volume of electricity supplied or distributed (in the residential sector this is often calculated through customer numbers serviced, and not actual volume of electricity) (Lees, 2007). Additional policy objectives can be incorporated through target-setting, for example in the UK and Belgium obligated companies are required to ensure that a proportion of their targets are met in low income households (Lees, 2007). An understanding of what is required to achieve targets, the cost of energy savings, is important to ensure that the scheme is effective, but also that the costs of the scheme are not punitive on energy consumers.

\subsubsection{Point of regulation or obligation}

There are a number of potential points of regulation, or obligation in a WCS, including energy suppliers, distributors, producers with direct contracts with customers, or large electricity consumers (Capozza, 2006). Electricity suppliers are identified as being good candidates for regulation (Oikonomou, 2004) as they have the resources and market power to support the transition to cleaner and less emissions- intensive energy services, and with careful policy design can be incentivised to shift from an energy sale focus, to that of selling energy services. Suppliers can also use existing infrastructure, technological know-how and client relations to implement energy efficiency projects quickly and effectively (Oikonomou, 2004). The limited number of suppliers in an energy system reduces administrative and compliance costs.

Different to an emissions trading scheme, the point of regulation in a WCS is typically not where the energy-saving activity occurs. For reasons of ease of monitoring, compliance and administration, regulation tends to lie with the energy suppliers or distributors, whereas the savings occur with the end consumers. Intermediaries in the form of ESCOs whose core business is to identify and implement energy savings may perform this role, stimulating the development of the energy service industry

In practice, a WCS will always involve electricity as an energy carrier. Natural gas is very often included (France, Great Britain, Italy), and in France domestic fuel for cooling and heating is also a component (Capozza, 2006). The energy carrier involved will be determined by the energy policy objectives of each country. There are no examples of transport being included in a WCS (Capozza, 2006).

\subsubsection{Eligible technologies}

Energy-efficiency technologies can be prescribed in the design of the WCS. This is not considered optimal, as it can encourage lock-in to levels of technological development, only enabling access to static efficiencies (Oikonomou and Patel, 2004). Flexibility in technology choice is an important component of an economic instrument in achieving dynamic and ongoing cost efficiencies. That the scheme targets are set at an appropriately stringent level is an important component in incentivising technological innovation. Support for specific technologies through additional policy measures such as subsidies may assist government in pursuing additional energy efficiency objectives, but may simultaneously introduce inefficient distortions into the market.

\subsubsection{Monitoring and verification}

Issues pertaining to monitoring and verification are of particular importance for the costeffectiveness of implementation and verification of energy efficiency schemes. Actual 
measurements or deemed or engineering estimates of energy savings can be used to monitor the performance of a scheme. Deemed, or ex ante, measures have been used in the residential sector where an average energy-saving figure is used for each household even though the actual energy saving will vary from household to household. The large numbers of households involved will ensure accuracy. In the UK, this feature has led to monitoring costs being less than one percent of the cost of energy supplier expenditure (Lees, 2007). In the commercial and industrial sectors however, actual measurements are required given the scale of savings involved. An alternative is to use engineering estimates or scaling of known energy savings according to the size of the operation to provide a simple and yet robust alternative (Lees, 2007).

Ex ante monitoring procedures are strongly favoured by WCSs currently implemented (Capozza, 2006), as they significantly reduce administrative and compliance costs. Ex ante methods seem to be well accepted by stakeholders, and can be easily updated with baseline changes. Given that conservancy is an important criteria for the development of ex ante procedures, a comparison with ex post (actual) measures show that often emissions savings are underestimated. However, confirming the additionality of projects is easier under an ex post system (Capozza, 2006).

\subsubsection{Trading}

Given that there is little length of experience in trading WCSs, lessons are few. In European schemes where energy suppliers have energy efficiency obligations which are realised through their customer's reduction activities, a question has arisen around whether competitive market forces amongst the suppliers would not achieve the objective of trading in a less complicated manner (ie, competition for energy service delivery to customers) (Capozza, 2006). However, the flexibility of a market in energy efficiency credits is still held to realise efficiency gains which would not be available in the absence of trading (Capozza, 2006).

\subsubsection{Banking}

Most schemes allow for the transference of energy savings from one target period to the next, through the banking of certificates. This has positive benefits for both the obligated company and energy efficiency industries as it allows flexibility and phased investment decision making. When banking was not allowed in the UK in 2000, targets were met early and whilst waiting for a new period to start there was a marked drop in activity which had negative implications for the insulation industry at the time (Lees, 2007).

\subsubsection{Additionality and baselines}

Ensuring that energy efficiency activities are additional (in addition to those that would have occurred in the absence of the WCS) is critical to ensuring scheme performance. This is more difficult in an environment where there are numerous interacting energy policy instruments to be accounted for. Baselines are related to additionality concerns, and setting the correct baseline will directly determine scheme performance. Overly cumbersome additionality and baseline rules will deter participation in the scheme, and the incentive to overachieve targets (Capozza, 2006).

\subsection{Lessons from international experience}

WCSs theoretically guarantee that a certain volume of energy savings is achieved. Thus, the policy benefit is known upfront, but not the cost of achieving these savings, which is determined by the market if trading is allowed for. The upfront uncertainty around compliance costs can deter investment in energy efficiency initially (Capozz, 2006). The introduction of a price mechanism, through trading, allows for the least cost achievement of targets. There has been little experience of trading white certificates to date, but most policymakers believe that incorporating trading in the future will enhance the performance of schemes (Lees, 2007; Capozza, 2006). 
Depending on the mechanism through which targets are allocated to sectors and participants, trading schemes need not have any burden on public budgets. European evidence suggests that the costs to government lie in the region of 1-2 percent of energy bills (Lees, 2007). Depending on the size threshold to entrants, together with other design considerations, transaction costs can be substantial, and WCSs may require costly harmonisation with other energy policies (EuroWhiteCert Project, 2006).

WCSs can stimulate a market for energy services, and the growth of the ESCO sector as demonstrated by the New South Wales GGAS scheme (Capozza, 2006). A major benefit of WCS has been found to be the systematic measurement, tracking and accounting of energy efficiency activities. This is an important aspect to both greenhouse gas and energy efficiency policy objectives. (Oikonomou, 2004). European experience has shown that a WCS can be successfully implemented in both monopolistic and liberalised energy markets, and that it can develop with the energy sector as it transitions from one to the other (Lees, 2007).

Certain criteria have been observed as being important for the success of a WCS (Lees, 2007). It is important that the point of regulation is very clearly defined in the energy supply chain. Additionality must be addressed, particularly where there are large numbers of emission reduction activities. Regulatory certainty is highly advantageous, stimulating the market and investment decisions.

Interaction with other policy mechanisms in the energy sector requires further investigation, but there are grounds for double counting and additionality concerns, together with ensuring that consumers do not bear the costs of the schemes if compliance costs are passed through (Lees, 2007, Capozza, 2006, Oikonomou, 2004). The Italian, French and UK schemes do not overlap with other policy instruments, whilst the New South Wales Scheme is embedded in the GGAS, a greenhouse gas emissions cap-and-trade scheme (Capozza, 2006). Design of the interlinking schemes is determinant of the outcome.

Experience is inconclusive around the ability of WCS to stimulate the introduction of new technologies. The UK EES did not see many new technologies being introduced (Lees, 2007), whereas the experience of France indicates that a WCS speeds up the diffusion of efficient technologies, through the stimulation of a market in operators who directly engage with efficient equipment dealers (Capozza, 2006). On balance, the performance of WCS compared to other policy instruments for incentivising energy efficiency within an energy system has not yet been sufficiently studied (Capozza, 2006).

\subsection{White certificate trading and interaction with greenhouse gas mitigation policy instruments}

Energy efficiency activities achieve both the objective of conserving energy, and in most circumstances, reducing GHG emissions. There is therefore the potential that these activities can be targeted by both types of policy mechanisms. Energy efficiency activities also represent some of the least costly greenhouse gas mitigation activities available to economies. Given the importance of appropriate greenhouse gas mitigation scheme design within the context of longterm policy certainty and the constraints of short-term gaps in information, WCSs may offer attractive interim greenhouse gas mitigation instruments, which could evolve or be superceded by alternative policy options.

When considering interaction or integration between WCSs and a greenhouse gas mitigation policy instrument it is important to note that emissions reductions under a WCS are by their nature relative whereas many greenhouse gas mitigation policy instruments, such as cap-andtrade schemes, involve absolute targets. Interlinkages between the two will have to specifically account for this difference in order to avoid leakage of emissions reductions from the absolute sector. The interaction between the UK Climate Change Agreement participants and the direct participants in the UK Emissions Trading Scheme demonstrates a complex mechanism for coping with relative versus absolute reductions, it is possible to achieve but increases the administrative complexity of the policy environment. 
Additionality is also a concern when considering the interaction of WCS with other energy and emissions mitigation policy instruments. Should energy efficiency activities be required under separate schemes and regulations, their crediting under a WCS will not result in additional energy savings. Double counting may also present a problem if the same activities are claimed under different schemes (for example an emissions trading scheme and a WCS). Co-ordination of the registration of activities under the different schemes is therefore important.

Another consideration for the interaction between WCS and direct greenhouse gas mitigation policy options is that because of the prevalence of negative cost mitigation options in the energy efficiency realm, WCS may favour actions which are easy to implement and measure. This is both an advantage and disadvantage of these schemes.

International experience suggests that white certificates can be fully fungible with an emissions trading scheme, as long as double counting rules are firmly in place (GGAS), and the design of the schemes are compatible. For example, interaction between the EU Emissions Trading Scheme and a possible WCS is limited by the fact that the obligations introduced by the two directives concern different actors within the energy sector (power producers and energyintensive industries vs. energy distributors (EuroWhiteCert Project, 2006).

\section{WCS as a greenhouse gas mitigation policy option for South Africa}

\subsection{Relevant characteristics of the South African energy sector}

Energy emissions constitute 80 percent of the South African greenhouse gas emissions inventory (RSA 2004; Van der Merwe \& Scholes 1998), with energy efficiency measures in industry, commerce and the residential sector representing the bulk of negative cost mitigation options available in the economy. Therefore energy efficiency clearly plays an important role in the country's mitigation strategy for the short-to-medium term at least.

The importance of energy efficiency as a greenhouse gas mitigation instrument is further prioritised by the current energy crisis in the country. As is described in greater detail in the paper on Emissions Trading, energy efficiency is a mainstay of the country's response to the crisis, under the policy objectives of energy security and safeguarding economic growth.

The primary energy carriers in the South African energy sector are electricity, coal, liquid fuels and natural gas, with coal providing the overwhelming majority of the country's energy requirements, representing the primary fuel for electricity generation and feedstock for Sasol's coal-to-liquids refinery. Eskom, the national utility, generates and transmits the overwhelming majority of electricity within the country, under a monopolistic market structure. The government embarked on an electricity sector liberalisation path in the late 1990s, but this has been substantively abandoned due to the current supply crisis. Elements remain, however, with 30 percent of generation required to come from independent power producers in the future although Eskom will remain the sole purchaser of electricity coming onto the grid.

South Africa has developed a traditional competitive advantage in the area of energy-intensive industry, particularly mining, due to its historically cheap electricity supply. Low-cost electricity has also resulted in inefficiencies. Therefore, there are real competitive issues faced by industry, particularly export oriented sectors, as they will need to adjust to an environment of higher electricity tariffs going forward. To date, Eskom has run a Demand Side Management Programme which has subsidised the capital costs of energy efficiency and DSM projects out of a levy on electricity tariffs. There is therefore some experience within the country on monitoring and evaluating demand savings, although this programme has not stimulated the ESCO sector as anticipated. 
An Energy Efficiency Accord is in place between business and government in support of the government's 12 percent energy efficiency target for 2015. The accord is voluntary, and has 44 signatories to date (NBI, 2009).

As with many developing countries, South Africa faces the distributional challenge of making energy accessible and affordable to the poor, in the face of rising energy costs and pressures to consider the environmental costs of emissions intensive power generation. Poverty alleviation and job creation are the mainstays of the emerging government policy post the change of leadership within the ANC.

\subsection{Current energy sector policy context}

In response to the energy crisis in the country, the Power Conservation Programme being developed by Eskom has a 10 percent national reduction in electricity consumption as its objective, achieved through mandatory quotas on large targeted energy users under the Energy Conservation Scheme, and through pricing and demand-side management interventions for its smaller customers (Eskom, 2008c).

The ECS starts with large consumers using above $25 \mathrm{GWh}$ in both the private and public sectors under a voluntary Initial Phase (Eskom, 2008b), whilst the necessary regulatory environment is being created for mandatory targets. Targets are allocated according to the baseline period of October 2006 to September 2007, chosen due to there being little loadshedding over this time. Work is underway to consider whether differentiated targets will be applied to sectors according to their energy saving potential. The scheme does anticipate there to be a trading mechanism, referred to as the 'Right to consume'. The mechanisms for this trading component are currently under development. In the second phase it is anticipated that users above $100 \mathrm{MWh}$ per year will be included, which represents around 75 percent of total electricity consumption (Eskom, 2008c). The penalty for non-compliance is proposed as a steeply escalating tariff structure once an individual user's target is exceeded, with an electricity cut-off for repeat offenders.

The potential for scheme failure or underperformance is a critical issue for Eskom, as it will jeopardise the electricity supply system as a whole. The role of distributors in monitoring and implementing the ECS is important, and the number and variance in these (180 in total) presents significant challenges (Eskom, 2008c).

The ECS therefore represents a WCS in a fairly advanced stage of design, and with significant government and industry stakeholder backing. Aspects of incentives and trading to optimise uptake and cost efficiency are provisionally included in its design. The provision for flexibility for those sectors least able to conserve power gives the potential to safeguard against competitiveness concerns.

In its current design and context, the ECS is not being positioned as a greenhouse gas mitigation mechanism. Its primary objective is to avoid disruptions to electricity supply. However, from the perspective of emissions mitigation, it represents a progressive policy mechanism which targets low cost emissions reduction and which is in advanced stages of development.

\subsection{WCS as a greenhouse gas mitigation instrument in South Africa}

Given the advanced level of development of the PCP and ECS in South Africa, the primary intention of this paper is not to critique the appropriateness of a WCS as an energy efficiency policy mechanism for the country, but rather to explore its value as a greenhouse gas mitigation mechanism. However, because one of the components of this is the likelihood of a WCS performing in the South African context, this is considered in the light of international experience in WCS. As there is little literature or international evidence on the topic of WCS as an emissions mitigation instruments, nor on their application to developing countries, therefore the discussion in the remainder of this paper is largely exploratory in nature, posing many questions for further research. 


\subsubsection{Comments based on the application of theory and international experience to the South African context}

Regulatory policy theory suggests that different policy objectives should be individually targeted through separate policy instruments. This would suggest that targeting greenhouse gas mitigation through a WCS is likely to be inefficient and could lead to potential policy distortions. The double-counting of reductions is also a concern when too many policy instruments are employed for a similar objective (BRC, undated).

Given that a WCS achieves relative rather than absolute emissions reductions, this will always limit its use as a greenhouse gas mitigation instrument where an absolute level of greenhouse gas emissions reduction are required, such as South Africa in the long term. In South Africa in particular, the primary intention of the ECS is to create space on the grid to supply new connections until new capacity can come on line (Eskom, 2008c). The extent to which energy savings are entrenched and long term in a WCS is therefore important from an emissions mitigation perspective. The ability of a WCS to stimulate innovation and adoption of new technologies is also therefore relevant.

Lack of experience with trading, and an energy sector unfamiliar with how a market operates may indicate that a WCS including trading is less appropriate in a developing country situation. Trading requires financial infrastructure and capacitated market players (Lees, 2007). However, the financial benefits of a WCS may still be available to participants without a full trading mechanism. South Africa's financial sector is well advanced, and this may mitigate this concern.

The use of deemed savings calculation methods may reduce the administrative strain of a WCS, although this may still require capacity to develop. Accurate and timely monitoring and compliance evaluation is crucial to the performance of a market mechanism for greenhouse gas mitigation (see the Emissions trading paper). South Africa's experience in DSM provides it with some capacity in this regard. Technical knowledge, administrative capacity, and monitoring and verification challenges are not held to be insurmountable though (Lees, 2007).

Where the ECS has a very strong advantage as a greenhouse gas mitigation policy instrument is related to timing and political support. Its development has been prioritised due to the energy crisis, and it presents an already existing instrument targeting the technologies identified in the LTMS under the 'Start now' strategic option (see the Emissions trading paper in this series). The ECS could therefore potentially be considered as a central component of a suite of greenhouse gas mitigation policy instruments. There may be the opportunity to expand the ECS in the medium term to include absolute emission reductions, or to provide baseline-and-credit projects into a cap-and-trade emissions trading scheme. The point of regulation of the ECS (large energy consumers) presents one of the most appropriate points of regulation for an emissions trading scheme (see the Emissions trading paper in this series), and it is not clear whether South Africa has the capacity to administer more than one such scheme given capacity constraints and the size of its economy. However, whether the ECS could play a central role in the country's suite of greenhouse gas mitigation policy instruments will depend on its performance and flexibility of design, and the extent to which its current proponents are open to the possibility of alignment.

Finally, from a fiscal budgetary perspective, a WCS has a low cost to government, important in a country such as South Africa where there are many competing, and perhaps higher priority demands on government expenditure than greenhouse gas mitigation.

\subsubsection{Areas for further research}

There is limited experience and therefore analysis on WCS available to date, and even less on the potential interaction and linkages of WCS and emissions trading schemes and the appropriateness and role of WCS as greenhouse gas mitigation policy instruments. The following areas for further research are highlighted as being particularly relevant to the objectives of this paper, and the South African greenhouse gas policy context: 
- What is the role of a WCS as a greenhouse gas mitigation policy instrument in a developing country?

- How could the ECS contribute towards South Africa's greenhouse gas mitigation trajectory and policy framework to achieve its reduction targets? Does the New South Wales GGAS scheme offer any insights into the combination of baseline-and-credit energy efficiency and both emissions trading and green certificate schemes?

- Is a white certificate scheme more efficient in eliciting energy efficiency activities because it is focused solely on this objective, or would an emissions trading scheme encompassing emission reduction opportunities from a number of activities result in greater diversity of costs of reduction opportunities, and therefore cost efficiency?

- How can it be ensured that the energy efficiencies achieved through the ECS are longterm and sustainable in nature?

- How can the RTC trading elements of the ECS be designed to potentially allow for the inclusion of additional greenhouse gas mitigation sources in the future? Is this desirable?

- What are the lessons from other countries' experience regarding the integration of WCS into greenhouse gas policy frameworks (with a focus on the UK and Australian experience)? 


\section{References and bibliography}

Better Regulation Commission (undated). Regulating to Mitigate Climate Change, a Response to the Stern Review

Capozza, A. (2006). Market Mechanisms for White Certificates Trading. International Energy Agency Implementing Agreement on Demand-Side Management Technologies and Programmes. IEA DSM Task X1V Final Report

Crossley, D, Dr., (2005). The White Certificate Scheme in New South Wales, Australia., Presentation IEA Demand Side Management Programme Task 14 Workshop on White Certificates, Paris, France 14 April 2005. Energy Futures, Australia

Department of Minerals and Energy., (2005). Energy Efficiency Strategy of the Republic of South Africa. South Africa

Energy Sector Management Assistance Program (2005). Implementing Power Rationing in a Sensible Way: Lessons learnt by international best practices. World Bank. ESMAP website: www.esmap.org

Energy Development and Research Centre (2005), based on the 1994 National GHG Inventory, University of Cape Town

Eskom (2008a). Electricity Conservation Scheme - Interim Rules Version 7. November 2008

Eskom. (2008b). Fact Sheet: Power Conservation Programme-managing demand and making space for growth South Africa's Current Energy Crisis.

Eskom., (2008c)., Developing a Power Conservation Programme for South Africa. Presentation to NERT, September 2008

EuroWhiteCert Project., (2006). White Certificates and interactions with other policy instruments Work Package 3.3., European Commission Intelligent Energy Programme

EuroWhiteCert Project., (2006). White Certificates: concept and market experiences. March 2006; Accessed October 2008, http://www.eurowhitecert.org

EuroWhiteCert Project., (2006). White Certificate Schemes and European Emissions Trading System,(2006), Work Package 3.1. European Commission Intelligent Energy Programme, March 2006

Forum for Economics and Environment., (2002). Environmental economics and natural resource policy analysis, Training Manual Draft 1, Pretoria, South Africa.

Government of South Africa., (2008). Government outlines vision, strategic direction and framework for $\begin{array}{llll}\text { climate } & \text { policy, } & \text { Accessed } & \text { November }\end{array}$ http://www.info.gov.za/speeches/2008/08072816451001.htm

Greenhouse Gas Reduction Scheme., (2008). Introduction to the Greenhouse Gas Reduction Scheme (GGAS). www.greenhousegas.nsw.gov.au Accessed October 2008 (10)

Greenhouse Gas Reduction Scheme., (2007). Fact Sheet - How do I calculate my target. www.greenhousegas.nsw.gov.au Accessed October 2008

Greenhouse Gas Reduction Scheme., (2007). Fact Sheet - Summary of the scheme. www.greenhousegas.nsw.gov.au Accessed October 2008

Grubb M. (2006). EU ETS and the future. Presentation to Point Carbon Conference, Copenhagen, February 2006.

International Energy Agency (2006). Market Mechanisms for White Certificate Trading. Implementing agreements on Demand side management technologies and programmes.

International Energy Agency (2005). Saving electricity in a hurry: dealing with temporary shortfalls in electricity supplies.

Januzzi G (2005) Power Sector reforms in Brazil and its impacts on energy efficiency and research development activities. Journal on Energy Policy, Volume 33, pp. 1753-1762,

Jones, J., (2005). Energy Efficiency Commitment - The Way Forward. Presentation., DEFRA, United Kingdom

Lees, E., (2007). European Experience of White Certificates. World Energy Council

LTMS Cabinet release www.deat.gov.za

National Business Initiative (NBI) www.nbi.org (accessed 17 February 2009)

New South Wales Government, Department of Energy, Utilities and Sustainability,. Extending the Greenhouse Gas Abatement Scheme. Policy Paper. New South Wales Government, New South Wales, Australia (9) 
OFGEM., (2008). A review of the Energy Efficiency Commitment 2005-2008.

OFGEM., (2008), Second Annual Report 2003/2004 on Renewable Obligation, (accessed November 2008) www.ofgem.gov.uk

OFGEM., Carbon Emission Reduction Target (CERT) (accessed November 2008) www.ofgem.gov.uk/Sustainability/Environment/EnergyEff/Pages/EnergyEff.aspx

Oikonomu V., Rietenberg M., and Patel M., (2006). An ex-ante evaluation of a White Certificate scheme in The Netherlands. Journal on Energy Policy. Volume 35. Pp. 1147 - 1163.

Oikonomou., V., (2004). The “White and Green" Consortium., A qualitative analysis of White, Green Certificates and $\mathrm{EU} \mathrm{CO} \mathrm{CO}_{2}$ allowances. Phase II of the White and Green project, The "White and Green" Consortium., August 2004, Utrecht University, Copernicus Institute

Oikonomou, V., Patel, M., (2004) An inventory of innovative policies and measures for energy efficiency. Phase I of White and Green Project., The "White and Green" Consortium, Utrecht University, Copernicus Institute

Panayotou, T. (1994). Economic instruments for environmental management and sustainable development, Environment and Economics Unit, United Nations Environmental Programme

Sanders, J., Clubb, D., (2005). White Certificates in the UK., Presentation, Mid Wales Energy Agency, May 2005.

Sonjica, B., (2008). Background notes on the national electricity emergency programme., Speech, 25 January 2008. Department of Minerals and Energy

SBT (Scenario Buidling Team) 2007. Long Term Mitigation Scenarios: Strategic Options for South Africa. Pretoria Department of Environment of Environmental Affairs and Tourism. www.environment.gov.za/HotIssues/2008/LTMS/A\%20LTMS\%20Scenarios\%20for\%20SA.pdf. Accessed 15 October 2008.

Scenario Building Team., (2007). Long Term Mitigation Scenarios: Technical Summary. Department of Environment Affairs and Tourism, Pretoria, October 2007

South African National Treasury, (2006), Tax Policy Chief Directorate, April 2006. A framework for considering market-based policy instruments to support environmental fiscal reform in South Africa. Draft policy paper

UK Department of Environment, Food and Regional Affairs (2007). Consultation on the recommendations of the climate change simplification project: climate change instruments, areas of overlap and options for simplification

UK Department of Trade and Industry (2003). Energy White Paper. http://www.berr.gov.uk/files/file10719.pdf

Van der Merwe, MR \& Scholes, RJ (1998). South African Greenhouse Gas Emission Inventory for the years 1990 and 1994. Pretoria, National Committee on Climate Change.

Winkler, H (Ed) 2007. Long Term Mitigation Scenarios: Technical Report. Prepared by the Energy Research Centre for Department of Environmental Affairs and Tourism, Pretoria, October 2007. www.erc.uct.ac.za/Research/LTMS/LTMS-intro.htm Accessed 30 October 2008.

Witters, J., (2007). Promotion of Energy End-use Efficiency and Energy Services: Implementing Directive 2006/32/EC in the UK., Letter to DEFRA 25 October 2007, OFGEM

www.southafrica.info accessed 17 Feb 2009. South African Energy Sector 